\title{
A NOMENCLATURALLY ACCEPTABLE RANK FOR THE SUNDEW EPITHET “OBOVATA”
}

\author{
JAN SCHLAUER • Zwischenstr. 11 • 60594 Frankfurt/Main • Germany • jan@ carnivorousplants.org
}

Keywords: taxonomy: Drosera.

The naming of plants for scientific purposes is governed by a set of rules that have been coined in order to reduce ambiguity and confusion. This set of rules is called the International Code for Botanical Nomenclature (ICBN), and the text is published online (http://ibot.sav.sk/icbn/main.htm).

Naturalists familiar with the circumboreal sundews will probably recognize the difference between Drosera anglica and the hybrid between D. anglica and D. rotundifolia. Those interested in sundew phylogeny should also know D. anglica is an amphidiploid (stabilized polyploid) hybrid between $D$. linearis and $D$. rotundifolia.

What has tricked many European botanists (all circumboreal sundews have been described by European botanists) is the circumstance that D. linearis (described in 1822 by a European botanist) only occurs in a limited area in North America, so it is the only naturally occurring boreal sundew species that does not have a circumboreal range. Thus, Europeans did not know the parent species well and by consequence they ignored the hybrid origin of $D$. anglica for a long time. This time was long enough to have the hybrid between $D$. anglica and D. rotundifolia discovered, described and named as D. obovata or D. ×obovata to indicate hybrid nature (cf. ICBN Art.H.1.1. "Hybridity is indicated by the use of the multiplication sign $\times$ or by the addition of the prefix "notho-" the term denoting the rank of the taxon."), again by European botanists (in 1826).

Technically, D. ×obovata is the name of a taxon at the rank of species (which is purely a question of classificatory ranking and independent from the hybrid or non-hybrid nature of a taxon). If it is taken into account that it is a hybrid (or of hybrid origin), it can be termed a "nothospecies" (cf. ICBN Art.H.3.3. "For purposes of homonymy and synonymy the multiplication sign and the prefix "notho-" are disregarded.").

One of the fundamental principles of botanical nomenclature is there can only be one accepted name for any given taxon at its particular rank, and this should be the first name that has been published according to ICBN rules ("legitimate") for this taxon at this rank (priority, cf. ICBN Art.11.4. "For any taxon below the rank of genus, the correct name is the combination of the final epithet of the earliest legitimate name of the taxon in the same rank, with the correct name of the genus or species to which it is assigned, except in cases of limitation of priority", none of the mentioned cases of limitation applies here).

For hybrids (including stabilized hybridogenic taxa of whatever age), there is an extension of the principle of priority in order to avoid the creation of multiple names for taxa at the same rank spanning the taxonomic range from one parent to the other. This extension mandates that there must be only one (again the earliest legitimate one) name at the rank of the parent taxa (ICBN Art.H.5.1. "The appropriate rank of a nothotaxon is that of the postulated or known parent taxa. H.5.2. If the postulated or known parent taxa are of unequal rank the appropriate rank of the nothotaxon is the lowest of these ranks.") for all hybrids that have the same parent taxa.

ICBN Art.H.4.1. "When all the parent taxa can be postulated or are known, a nothotaxon is circumscribed so as to include all individuals (as far as they can be recognized) derived from the crossing of representatives of the stated parent taxa (i.e., not only the Fl but subsequent filial generations and also back-crosses and combinations of these). There can thus be only one correct 
name corresponding to a particular hybrid formula; this is the earliest legitimate name in the appropriate rank, and other names to which the same hybrid formula applies are synonyms of it."

All the parent species of $D$. anglica are known (D. linearis and D. rotundifolia). After rejection of the ambiguous name $D$. longifolia, $D$. anglica is the earliest (1778) legitimate name for a taxon resulting from hybridization of $D$. linearis and $D$. rotundifolia. Drosera obovata is the name for a taxon resulting from the hybridization of $D$. anglica and $D$. rotundifolia, i.e., technically a back-cross with one of the parents of $D$. anglica, not involving any different parent taxa.

Thus, the principle of priority precludes acceptance of the name D. obovata at its original (species) rank. There is, however, no reason to prevent naming this taxon at a lower rank under D. anglica.

As the hybrid between $D$. anglica and D. rotundifolia is usually sterile, it rarely occurs far from the parent species, although it may outcompete one of the parents due to hybrid vigour. From a chorological perspective it does not have a range that exceeds the range of overlap of the two parents, so it can be regarded as essentially sympatric with both.

The present author's concept for infraspecific classification in Drosera is to distinguish subspecies where the taxa are allopatric (whether derived from allopatric differentiation or from comparable trends of independent chorology), and to distinguish varieties where taxa are sympatric (chorologically coherent).

The acceptable (and earliest legitimate) name for the hybrid between $D$. anglica and $D$. rotundifolia is for the reasons above $D$. anglica var. obovata. This combination has already been published by Planchon (Ann. Sci. Nat. III.ser. 9: 200, 1848).

The hybrid nature of the taxon may be indicated by calling it Drosera anglica nothovar. obovata Planch. (pro var.) (ICBN Art.50.1. "When a taxon at the rank of species or below is transferred from the non-hybrid category to the hybrid category of the same rank (Art.H.10.2), or vice versa, the author citation remains unchanged but may be followed by an indication in parentheses of the original category.").

\title{
Writings from the Readership
}

\section{FURTHER COMMENTS ON FAUNA TRAPPED BY EuCNIDE URENS (PARRY EX GRAY) PARRY}

\author{
JANE M. Bowles • Department of Biology • University of Western Ontario • London, ON, N6A \\ 5B7・Canada • jbowles@uwo.ca
}

Keywords: observations: Eucnide urens.

This follows up on the articles about the insecticidal properties of Eucnide urens by Michael Metzler (2006) and Barry Rice (2006). In February 2008 I returned from California where, like Michael Metzler, I went for a hike in Mosaic Canyon, Death Valley and noticed that the lower surfaces of the leaves of Eucnide urens (desert stingbush or rock-nettle) were covered with dead dipteran flies. In my case it was cool and relatively wet and the plants were not flowering, nor were there many insects flying about. The fly carcasses were dry and mummified and I found them only on one plant out of the dozen or so that I checked. Barry Rice had the insects identified for me, by Dr. Robert Bugg (University of California, Davis), as Peleteria sp. (Tachinidae), a fly that as a larva is parasitic on lepidopteran larvae, and which is nectarivorous as an adult. I did not touch the plant because it looked ferocious and I have long ago learned to be cautious about touching desert plants with silica hairs. I did notice however that while the upper leaf surface only had long straight hairs the lower surface had a few straight hairs, but many shorter blunt-looking hairs. I could not tell in the field if these were barbed or glandular, but a photo- 